\title{
A CRÍTICA COMO MÉTODO NO RETORNO A FREUD
}

Marta Regina de Leão D’Agord

Marta Regina de Leão
D’Agord
Psicóloga, mestre
em Filosofia,
doutora em
Psicologia;
professora do
Departamento
de Psicanálise e
Psicopatologia e
do Programa de
Pós-Graduação em
Psicologia Social
e Institucional
(Instituto de
Psicologia, UFRGS).

RESUMO: Em seu projeto de retorno a Freud, Lacan propõe um diálogo com outras disciplinas para a análise dos conceitos psicanalíticos. Neste artigo, analisa-se a contribuição de conceitos de Linguística, Lógica e Matemática para a formulação do conceito de sujeito do inconsciente, tal como encontramos no matema "um significante representa um sujeito para outro significante". O termo 'crítica' é referido à análise da racionalidade necessária para se atingir um conhecimento. Este trabalho mostra que a análise do conceito de sujeito do inconsciente conduziu Lacan à elaboração de uma lógica do significante. Esta lógica poderá ser nomeada como uma lógica psicanalítica.

Palavras-chave: Psicanálise, crítica, método, lógica.

ABSTRACT: The critique as method in the return to Freud. In his project of a return to Freud, Lacan proposes a dialogue with other disciplines for the analysis of psychoanalytic concepts. This paper presents an analysis of the contribution of concepts from linguistics, logic and mathematics in the elaboration of the concept of unconscious subject, as appears in the matheme: a signifier represents a subject to another signifier. The term critique refers to the analysis of rationality necessary to reach knowledge. This work concludes that the formulation of the concept of the unconscious subject leads Lacan to the development of a signifiant's logic. This logic may be named as a psychoanalytical logical.

Keywords: Psychoanalysis, critique, method, logic. 


\section{INTRODUÇÃO}

Este trabalho analisa, na obra de Jacques Lacan, momentos que indicam a apropriação da crítica como método para a realização do projeto de retorno a Freud. Ao longo dessa crítica é possível identificar a emergência de uma lógica do significante a partir da elaboração do conceito de sujeito do inconsciente. Esse processo encontra seu momento privilegiado quando Lacan interpreta a expressão "nur einen einzigen Zug" de FREUD (1921c/1976, p.117), "apenas um traço isolado" (FREUD, 1921c/1987, p.135), com os aportes linguísticos, lógicos e matemáticos.

O que seria uma lógica do significante? Tratar-se-ia de uma lógica no sentido do organon aristotélico, de instrumento para a produção de conhecimento? Se pensarmos que o instrumento é um conceito ou um modelo que não tem existência no real, mas que permite o acesso ao real, uma lógica seria um instrumento. Seria essa a função de uma lógica do significante? Um instrumento para acessar ou intuir o sujeito do inconsciente?

A leitura da lógica como instrumento permite uma interpretação do uso da topologia por Lacan. Sobre esse uso encontramos duas vertentes nas pesquisas atuais. Uma primeira vertente poderia ser chamada de comparativa, a outra de estrutural. Para Conté (1996), representante da vertente comparativa, as superfícies topológicas seriam modelos para explicar o sujeito do inconsciente. Entretanto, para os representantes da vertente estrutural (EIDELSZTEIN, 1992 e DOUMIT 1996), a topologia em Lacan é algo mais do que um modelo. Para Eidelsztein (1992), os esquemas, grafos, superfícies e nós têm a mesma estrutura do que se quer representar, a saber, o sujeito. Doumit (1996) também faz essa leitura, ao observar que Lacan elabora os lineamentos de uma lógica "com um estilo e uma linguagem tais que não se apresentam como exteriores ao objeto de que falam" (p.297).

Essas pesquisas trabalham com a hipótese de que Lacan buscava, no campo da Matemática e da Lógica, uma forma de acesso simbólico ao real, isto é, um método. "Para Lacan, observa Zizek (1997), a ciência moderna tem relação com o Real (matemático) que se encontra sob o universo simbólico” (ZIZEK, 1997, apud GLYNOS \& STAVRAKAKIS, 2001, p.4).

Considerando-se que o único acesso ao real se dá pela escrita, para se fazer ciência é preciso criar uma forma escrita, isto é, simbólica, de acesso ao real. Portanto, o esforço de Lacan ao criar esquemas e grafos (modelos topológicos bidimensionais) e, mais tarde, trabalhar com toros, cross-caps, garrafa de Klein e enlaces borromeanos (modelos topológicos tridimensionais) teria como objetivo a busca de uma escrita lógico-matemática e alfanumérica do real.

Lacan empregou, primeiramente, o termo 'categoria' para falar de Real, Imaginário e Simbólico, como letras para descrever três zonas distintas do seu esquema R. Mais tarde, substituiu a noção de categoria pela de dimensão, sendo 
a dimensão uma invariante topológica fundamental. E, por fim, a dimensão foi substituída pela noção de consistência na topologia dos enlaces borromeanos. Nessa trajetória, é possível mapear um projeto científico caracterizado pela busca de aperfeiçoamento de uma forma escrita para dar conta do sujeito do inconsciente.

Podemos demarcar um início dessa trajetória de delimitação do real no escrito “A carta roubada” (1956/1998), quando Lacan aborda o jogo do “par ou ímpar” e suas variações: sinais de mais (+) e menos (-) ou “cara ou coroa”. Para Matherat (2007), esse texto contém uma parte matemática que se apoia no exemplo de como uma cadeia significante pode fazer aparecer, enquanto estruturada, uma cadeia aleatória. A partir de um apólogo extraído do conto homônimo de Edgar Allan Poe (1809-1849), Lacan demonstra que, a partir de um primeiro lance, que pode ser cara ou coroa, inicia-se aleatoriamente uma sucessão de lances em que: cara sucede à cara; coroa sucede à cara; cara sucede à cara; coroa sucede à coroa; e assim por diante. Poderemos, então, elaborar uma combinatória com todas as possibilidades de seriação a partir de um primeiro lance.

Mesmo assim, o primeiro lance mantém-se não calculável, na medida em que depende apenas do acaso. O acaso do primeiro lance no jogo do cara ou coroa equivaleria ao real. Dado um primeiro sorteio ao acaso, uma estrutura poderá determinar as possibilidades dos novos sorteios. Com o cálculo das probabilidades, buscamos cercar e limitar o real por meio do simbólico. Quaisquer que sejam os resultados de uma série de sorteios ao acaso, esses resultados já entram em um sistema predeterminado, em uma estrutura que os determina. Porém, a estrutura simbólica não impede que o acaso continue existindo. Portanto, o simbólico não esgota o real.

\section{O PROJETO CRÍTICO}

Lacan (1953/1966) observou que a Psicanálise, como disciplina, devia seu valor científico aos conceitos elaborados no progresso da experiência de Freud. Entretanto, esses conceitos, por ainda estarem mal criticados, conservavam a ambiguidade da língua vulgar ["d'être encore mal critiqués et de conserver por autant la ambiguité de la langue vulgaire” (LACAN, 1953/1966, p.240-241)]. Ao designar como mal criticados os conceitos psicanalíticos, Lacan anunciava que a tarefa crítica estava incluída em seu projeto de "retorno a Freud".

O que seria uma crítica em Psicanálise? A pesquisa etimológica de Heidegger (1965/2001) indica que 'crítica', do grego crinein, significa diferenciar, realçar, deixar ver o diferente como tal em sua diferença. Nessa perspectiva, o que é diferente só o é porque é diferente com referência a algo. Atenção: caracteres gregos 
Uma crítica, na acepção preconizada por Kant, indaga de que modo a razão chega ao conhecimento, isto é, a crítica avalia as condições para o conhecimento, dados os limites da experiência. Trata-se, em Kant, de uma crítica enquanto estabelecimento de limites para a razão.

Diferenças e limites. Seriam essas as duas fontes críticas das quais se originaria o projeto lacaniano de retorno a Freud? A referência a diferenças e limites aparece no diálogo da Psicanálise com outros campos do conhecimento. Lacan (1953/1998) propõe a atividade comparativa enquanto busca de equivalências entre conceitos psicanalíticos e conceitos de outras disciplinas. "Parece-nos que esses termos [os psicanalíticos] só podem esclarecer-se ao estabelecermos sua equivalência com a linguagem atual da antropologia ou com os mais recentes problemas da filosofia, onde, muitas vezes, a psicanálise só tem a se beneficiar” (LACAN, 1953-1966/1998, p.241).

Os limites, no projeto crítico de Lacan, serão propostos a partir do estabelecimento de equivalências com a linguagem da Antropologia, da Filosofia e da Lógica. A atividade comparativa responderá, portanto, pela crítica enquanto limite. Por outro lado, há uma dimensão do benefício que a crítica poderá trazer para a Psicanálise, enquanto fundamentação teórica necessária para uma disciplina que pretenda valor científico. Esse benefício seria a afirmação do que é o próprio da Psicanálise, isto é, em que a psicanálise se diferencia das outras ciências.

Um terceiro aspecto do projeto crítico de Lacan tem como demarcador o uso das expressões “a experiência de Freud” e "a experiência freudiana”. Essas expressões, retomadas várias vezes por Lacan, seja nesse texto dos Escritos seja no Seminário, demarcam um distanciamento crítico em relação ao que provém da experiência freudiana. Consideramos que este terceiro aspecto do projeto crítico de Lacan caracteriza sua proposta de não romper com a terminologia, mas de contextualizar, na experiência freudiana, a origem dos termos.

É nessa perspectiva tríplice de crítica que é preciso considerar a leitura do termo freudiano einziger Zug por Lacan (1961-1962/1996). “Somente um traço isolado” (nur einen einzigen Zug) é uma expressão utilizada por Freud (1921c/1987) para se referir a uma identificação com apenas um traço de outra pessoa.

A leitura crítica que Lacan realiza do conceito de identificação pode ser analisada considerando as três vertentes que apontamos aqui. Há uma fundamentação teórica do conceito de identificação no diálogo com a Lógica e com a Linguística; há a afirmação da teoria psicanalítica com a elaboração do conceito de identificação simbólica, diferenciando-o do conceito de identificação imaginária. A identificação imaginária será caracterizada como biunívoca, tendo o estádio do espelho como paradigma. A identificação imaginária origina-se da imagem de si mesmo como uma totalidade que é antecipada pelo infans em seu encontro com a sua imagem refletida. Essa imagem oferecida pelo reflexo especular 
é correspondência biunívoca, e se assim não fosse, não geraria o júbilo como efeito da antecipação de uma imagem de totalidade. Já a identificação simbólica será comparada à função significante e seu paradigma será o traço unário. Se a primeira corresponde ao eu ideal, a segunda ao ideal de eu.

E, por fim, a noção de "um traço isolado", na obra de Freud (1921c/1987), oferece um ponto de partida para a concepção de lógica do significante. O que revela o projeto lacaniano de continuidade da pesquisa psicanalítica sem ruptura com a obra freudiana.

\section{A APLICAÇÃO DA CRÍTICA ENQUANTO MÉTODO NA LEITURA DO UNÁRIO COMO DIFERENÇA} “A abordagem moderna do Um é escritural, conforme o que um dia extraí de
Freud, o einziger Zug. Essa é a expressão com que Freud rotula uma das formas do que
chama de identificação. Eu a traduzi, de uma forma que persiste, por traço unário."
(LACAN, 1968-1969/2008, p.119)

Kant criticara o conceito filosófico de unidade, mostrando que a unidade não é o um, mas uma função, a função sintética. Lacan, por sua vez, vai mostrar que o traço unário da experiência freudiana é para ser considerado como uma função: a função significante. Assim, a identificação do sujeito psíquico é para ser buscada não em uma unidade, como um ser, no sentido de algo já dado, mas em uma relação entre significantes.

Lacan articula os designadores de Frege, o conceito de valor linguístico de Saussure, e a definição de signo de Peirce para pensar a função significante, isto é, o significante como o que pode ser apagado, isto é, que pode ser substituído por outro.

A diferenciação dos designadores entre Sinn e Bedeutung por Frege (1848-1925), posta em relação com a concepção de valor linguístico de Saussure (1857-1913) e com o fundamento do signo em Peirce (1839-1914), permitirá a Lacan fundamentar o conceito de sujeito do inconsciente com a concisão do matema "um significante representa um sujeito para outro significante”. A relação entre um significante e outro significante é que vai produzir um sujeito. Um significante sozinho nada produz. Por sua vez, a concepção de função do significante supõe um diálogo com a Matemática, mais especificamente com a teoria dos conjuntos. Tomemos o conceito de número para analisar qual seria a comparação possível com o conceito de sujeito do inconsciente.

Um número é uma propriedade de um conjunto. Se um conjunto tem a propriedade dois, dizemos que "nesse conjunto há dois elementos". Assim, o número 
dois poderá ser representado ou pelo algarismo dois ou pelo conjunto formado por dois elementos. Essa propriedade de um conjunto é também chamada de cardinal. Diferentemente do cardinal, o conceito de ordinal é relacionado à sucessão ou vizinhança. Qual é o número seguinte a um número dado? É aquele que se refere ao conjunto com um elemento a mais. Logo, o número seguinte é aquele que é representado por um conjunto onde há “Um a mais". Assim, para que um conjunto A seja diferente de um conjunto B, é preciso que haja pelo menos um elemento em A que não esteja em B, ou vice-versa. Este elemento vai ser o um mais, o que faz a diferença entre os dois conjuntos. Se definirmos um conjunto pelos seus atributos, pode haver um conjunto mesmo quando não existam elementos. Ou seja, o conjunto é uma abstração formada a partir de uma definição de atributo, por exemplo, o atributo "quadrados redondos".

Por sua vez, um atributo ou designador pode ser analisado como denotação ou como conotação. É nessa perspectiva que Frege diferenciou “o caráter informativo de duas afirmações de identidade que contenham termos correferenciais, distinguindo o referente (Bedeutung) de um nome do seu sentido (Sinn)" (BRANQUINHO, 2006, p.670). O objeto ao qual o termo se aplica é o referente. E o sentido do termo contém o modo de apresentação de sua referência.

Por exemplo, os nomes Edson Arantes do Nascimento e Pelé designam a mesma pessoa. Todavia, as frases: "Pelé é Pelé" e "Pelé é Edson Arantes do Nascimento" não têm o mesmo valor. "Pelé é Pelé” é uma frase que simplesmente expressa a identidade de uma pessoa consigo mesma. "Pelé é Edson Arantes do Nascimento", por outro lado, tem valor informativo. Uma pessoa que descobre que "Pelé" e "Edson Arantes do Nascimento" designam a mesma pessoa não está meramente descobrindo a relação de identidade que uma pessoa tem consigo mesma, pois isso ela já sabia, ao menos implicitamente. Os nomes Edson Arantes do Nascimento e Pelé têm a mesma referência, mas não têm o mesmo sentido.

É preciso, então, retomar o conceito de valor em linguística, o qual é constituído pelos princípios de troca e comparação. Pelo primeiro princípio, uma coisa dessemelhante é suscetível de ser trocada por outra coisa cujo valor resta determinar. Trata-se de uma significação. Pelo segundo princípio, coisas semelhantes podem ser comparadas com aquela cujo valor está em causa. Trata-se de uma oposição. Alguns exemplos, apresentados por Saussure (1916/1995), permitem compreender o alcance da concepção de valor em Linguística: O português carneiro ou o francês mouton podem ter a mesma significação que o inglês sheep, mas não o mesmo valor, pois ao falar de uma porção de carne preparada e servida à mesa, o inglês diz mutton e não sheep. Eis a diferença de valor entre as palavras sheep e mouton. Sheep tem a seu lado um segundo termo, mutton, o que não ocorre com a palavra portuguesa ou com a palavra francesa. 
A palavra sheep, pode significar carneiro, mas sheep, quando acompanhado por mutton, terá outra significação. Carneiro no contexto campo terá uma significação, mas carneiro, empregado em relação à mesa, terá outra significação. Há uma mudança de valor. Um significante (carneiro) produz uma significação (alimento) desde que posto em relação a outro significante (prato). Retomando os designadores, a palavra carneiro tem duas denotações (referentes): aquele animal e aquele tipo de carne. E a decisão a ser tomada quanto à significação em questão depende do contexto, isto é, do significante que vem antes ou depois no enunciado. Isto é, depende dos outros elementos do conjunto (enunciado) do qual faz parte a palavra carneiro.

O que é introduzido, através diferença entre as apresentações de uma referência, é a função significante. Os nomes Edson e Pelé, mesmo que sejam a mesma pessoa, designam, diferentemente, o mesmo referente. Eis a diferença significante. A função significante gera, por sua vez, a distinção entre a função conotativa e a função denotativa.

Outra diferença introduzida pela função significante será aquela entre as classes e os conjuntos. As classes respondiam pela relação de cada ente com determinada classe como um universo no qual ele estaria incluído ou não. Por exemplo, se um ente não estivesse incluído na classe $x$, ele estaria necessariamente incluído na classe não x, o complementar da classe. É preciso agora abordar as relações entre os membros de uma classe. É a essa questão que a teoria dos conjuntos responde. Pois não é apenas pela presença ou ausência de um atributo que é possível definir se determinado ente está incluído ou não em determinada classe. Logo, uma classe, enquanto universo, não é suficiente para trabalhar o conceito de identificação.

Lacan compara, então, o conjunto vazio ao Outro enquanto lugar dos significantes. Dada a propriedade “x é diferente de si mesmo”. Dado que não existe um elemento que seja diferente de si mesmo, esse é um conjunto vazio. O conjunto vazio é, portanto, um conjunto que existe, mas que não tem elementos. Pelo princípio da extensionalidade, poderemos afirmar que há apenas um conjunto vazio. Se tivermos dois conjuntos, A e B, com exatamente os mesmos elementos, então se trata do mesmo conjunto e não de conjuntos diferentes. Ou seja: A = B. Para um conjunto A ser diferente de um conjunto B, é preciso que haja pelo menos um elemento em A que não esteja em B, e vice-versa. Dessa forma, só há um conjunto vazio, pois se houvesse dois candidatos distintos, um deles teria que conter um elemento que não se encontrasse no outro. Caso contrário seria o mesmo conjunto, o conjunto vazio.

Assim como não há dois conjuntos vazios, não há Outro do Outro. Não há um sentido em um significante, assim como não há outro escondido atrás de um espelho. Não há nada senão a sucessão de significantes. Um corte nessa sucessão, 
enquanto reordenamento de significantes, será produzido pelo sujeito do inconsciente no ato falho, no chiste, no sonho e no sintoma. Essa ruptura é que faz com que surja a possibilidade de novos sentidos. Mas algo permanece o mesmo?

Lacan (1961-1962/2003) explica a identidade própria ao significante a partir de uma imagem criada por Saussure. Considerando-se “dois expressos Genebra-Paris das 8:45 da noite que partem com 24 horas de intervalo. Aos nossos olhos, é o mesmo expresso, e no entanto, provavelmente, locomotiva, vagão, pessoal, tudo é diferente” (SAUSSURE, 1916/1995, p.126). Ou seja, a realização material dos expressos é diferente.

Essa imagem permite ilustrar a concepção de que o traço unário se realiza pela sucessão na qual se agrega um a mais a cada vez, por isso, a cada vez diferente. O significante é fecundo porque não pode ser idêntico a si mesmo. No exemplo do expresso das 8:45 da noite, a diferença, o um a mais, relaciona-se às condições materiais diferentes, ou seja, a cada nova edição do traço, a realização material do traço é outra. Poderíamos nos surpreender com essa abordagem da identificação a partir da função significante? Não, se pensarmos que se trata do significante em oposição ao significado, e da precedência do significante sobre o significado. O leitor se surpreenderá ao perceber que se trata de tematizar a função significante comparando-a com a função matemática. Essa função matemática é possível encontrar também na concepção de fundamento do signo em Peirce. Vamos, pois, retomar a definição de signo para observar quando surge a função.

Um signo, ou representamen, para Peirce (1977),

“É aquilo que, sob certo aspecto ou modo, representa algo para alguém. Dirige-se a alguém, isto é, cria, na mente dessa pessoa, um signo equivalente, ou talvez um signo mais desenvolvido. Ao signo assim criado denominamos o interpretante do primeiro signo. O signo representa alguma coisa, seu objeto. Representa esse objeto não em todos os seus aspectos, mas com referência a um tipo de ideia, o fundamento do representamen." (PEIRCE, 1977, p.36)

O fundamento do signo poderia ser equivalente a um operador de função, uma função que definiria o contexto em que determinado signo é apresentado. Seria em comparação ao fundamento do signo que Lacan desenvolveria um conceito de função significante, isto é, uma abordagem do significante como uma produção de efeitos de significação? Peirce abordara a potencialidade do signo de produzir algo na mente de alguém a partir de uma relação entre um primeiro signo e um segundo signo. Aquilo que produz essa relação, e que é chamado de fundamento, é algo em comum entre o primeiro e o segundo signo. Assim, é esse fundamento, enquanto exterior à tríade (signo, interpretante, objeto) que produz a equivalência sem a qual não haveria produção de 
sentido. Esse fundamento que não é explicitado é como uma função significante, a produção de relações entre significantes sem que o sujeito o saiba.

\section{A FUNÇÃO SIGNIFICANTE}

“É o significante que corta, é ele que introduz a diferença como tal no real, e justamente na medida em que não se trata de diferenças qualitativas." (LACAN, 1961-1962/1996, p.58, tradução livre)

A elaboração de uma lógica do significante para a teorização sobre o sujeito do inconsciente tem dois parâmetros: o matema "um significante representa um sujeito para outro significante" e a formulação da identificação do significante. Vamos a seguir articular essas dois demarcadores.

O matema "um significante representa um sujeito para outro significante" introduz a serialidade. E uma série implica que sempre haverá um a mais, um significante a mais. Portanto, a serialidade introduz a diferença necessária a um significante para ser o que é. E aqui entra a questão matemática e também linguística da seriação. Esse conceito permite pensar a relação do sujeito do inconsciente a um primeiro significante que será denominado de 'traço unário'. É o que vem depois, isto é, o "um a mais" de uma série, que produz o sujeito para um primeiro significante, e este primeiro está perdido, está fora da série. Assim, ao buscar na Matemática uma homologia, Lacan introduz temas que seguirá abordando na década seguinte, quando o "a mais” será também um “a menos”, e ambos serão relacionados ao par ordenado $S_{1}$ e $S_{2}$, e à emergência do sujeito do inconsciente e do objeto a como mais-de-gozar.

Já o aporte para trabalhar o significante como diferença provém da Linguística. Saussure (1916/1995) aborda as diferenças e as oposições em um sistema de Língua. Um signo, como totalidade (significante e significado), é comparado a outro signo por oposição. Já a relação no interior do signo, a saber, entre significante e significado, é uma relação puramente diferencial. Assim, o estudo da linguagem se fundaria em oposições (distinções entre signos) e diferenciações fônicas (significantes) e conceituais (significados) que essas oposições implicam. Ou seja, a condição da oposição é a diferenciação.

Aplicado à unidade (signo), o princípio da diferenciação pode ser assim formulado: os caracteres da unidade se confundem com a própria unidade. “Na língua, como em todo sistema semiológico, o que distingue um signo é

\footnotetext{
1 "C'est le significant qui tranche, c'est lui qui introduit la différence comme telle dans le réel, et justement dans la mesure ou ce dont il s’agit n’est point des différences qualitatives."
} 
tudo o que o constitui. E a diferença é o que faz a característica, como faz o valor e a unidade" (SAUSSURE, 1916/1995, p.141).

Essa característica da diferença, aportada ao signo pelo significante, será destacada por Lacan na comparação entre a diferença significante e a diferença qualitativa. Essa última denota uma diferença de significado e é pela eliminação das diferenças qualitativas que a lógica atinge o princípio da identidade. Já a diferença significante conota a diferença em estado puro.

A operação que faz com que se gere uma identidade lógica ou matemática é aquela em que se abstrai de todas as diferenças qualitativas. Assim também o número é uma abstração, pois se trata de uma operação sobre, por exemplo, dois conjuntos contendo cada um três elementos, sejam esses conjuntos formados um por três frutas e outro por três animais. Abstraímos as qualidades dos elementos presentes e ficamos apenas com o número de elementos. Essa é a operação pela qual constituímos, na nossa infância, o conceito de número. Assim, do ponto de vista matemático, o real está aí, mas dele interessa a abstração número.

Ao ser definida essa identidade, atinge-se também o suporte do significante, a letra. Ou seja, pelo princípio da identidade, o significante é ainda o mesmo. Mas ainda não se chegou à diferença significante. Esta surgirá quando nos interrogarmos sobre qualquer série de traços entalhados sobre uma costela e concluirmos que não há semelhança entre eles. Isso é possível, na medida em que considerarmos a ordenação, a posição de cada traço em relação ao outro. E a ordenação desses traços, um depois do outro, é o efeito do simbólico sobre o real. Se os traços formam uma série, e, em uma série, como na série de conjuntos numéricos, um elemento sucede ao outro, está em posição diferente da posição do outro. Eis o conceito de significante: o significante como diferença de posição simbólica em uma série. A contribuição que Lacan buscou na matemática foi esse ordenamento simbólico do real.

Se o signo representa algo para alguém, é preciso alguém que já esteja aí como suporte do signo. O significante se distingue do signo porque manifesta a presença da diferença como tal e nada mais. O significante, não pode se definir senão como não sendo o que são os outros significantes. Do fato de ele não poder se definir senão justamente por não ser todos os outros significantes, depende essa dimensão de que ele não poderia ser ele mesmo. De onde surge outro ponto de partida, enunciado como “Um é o Outro”. "A não pode ser A”, o significante não pode ser idêntico a si mesmo. A função significante equivalerá à função da pura diferença. O significante introduz a diferença como tal no real. 


\section{CONSIDERAÇÕES FINAIS}

No projeto de retorno a Freud, o traço unário representa a leitura crítica de um termo freudiano na elaboração, por Lacan, da função significante. A função significante, por sua vez, é a articulação da concepção matemática do um e da concepção linguística do significante como diferença. A começar pela substituição de único por unário, em referência à teoria dos conjuntos, na qual conjunto unário é aquele que possui apenas um elemento. O traço unário, como um significante, é o que suporta o encadeamento ou a série. Nessa série, o significante primeiro é substituído por outro significante, e assim também acontece na metáfora. O acontecimento do sujeito do inconsciente toma a forma do apagamento ou substituição característica do significante. Se o signo peirceano tem no fundamento o seu suporte; o sujeito, por sua vez, encontrará seu suporte no significante, pois o significante representa o sujeito.

A substituição de $S_{1}$ por outro significante, $S_{2}$, inaugura uma série, e o encadeamento, a seriação, é o próprio simbólico. É aqui que entra o conceito de Outro como lugar, apresentado comparativamente à cadeia significante como uma relação nunca esgotada entre as possibilidades de uso de fonemas, isto é, o jogo entre semantemas e fonemas.

Encontramos, nessa elaboração lacaniana, o elemento fundamental do processo de simbolização já introduzido por Freud (1925h/1987) através da Verneinung, cuja conceituação também se situava a partir de uma análise comparativa com a Lógica. Um primeiro resultado da análise do projeto crítico de Lacan mostra que ele buscou o estabelecimento de um limite, isto é, o estabelecimento de uma regra primordial, como é apresentado no livro 9 do Seminário:

\footnotetext{
"Fazemos uma lógica do funcionamento do significante, pois, sem essa referência constituída como primária, fundamental, da relação do sujeito com o significante, o que eu adianto, é que ele é, propriamente falando, impensável." (LACAN, 19611962/2003, p.149)
}

Recebido em 27/2/2012. Aprovado em 5/7/2012. 


\section{REFERÊNCIASS}

BRANQUINHO, J. (2006). Enciclopédia de termos lógico-filosóficos. São Paulo: Martins Fontes.

CONTÉ, C. (1996). “Superfícies topológicas”, in KAUFMANN, P. (Ed.). Dicionário enciclopédico de psicanálise (p.527-541). Rio de Janeiro: Jorge Zahar.

DARMON, M. (1994). Ensaios sobre a topologia lacaniana. Porto Alegre: Artes Médicas.

DOUMIT, É. (1996). “Lógica”, in KAUFMANN, P. (Ed.). Dicionário enciclopédico de psicanálise (p.297-315). Rio de Janeiro: Jorge Zahar.

(1996). "Introdução à topologia”, in KAUFMANN, P. (Ed.). Dicionário enciclopédico de psicanálise (p.523-527). Rio de Janeiro: Jorge Zahar.

EIDELSZTEIN, A. (1992) Modelos, esquemas y grafos en la enseñanza de Lacan. Buenos Aires: Manantial.

FREUD, S. (1976) Gesammelte Werke. 8 ed. Frankfurt a. Main: Fischer.

(1921c) "Massenpsychologie und Ich-analyse”. Bd.XIII, p.71-161.

(1925h) “Die Verneinung”. Bd. XIV, p.372-377.

. (1987) Edição standard das obras psicológicas completas de Sigmund Freud.

2 ed. Rio de Janeiro: Imago.

(1921c). "Psicologia das massas e análise do eu”, v.XVIII, p.89-179.

(2007). Escritos sobre a psicologia do inconsciente, v.III. (1925h). “A negativa", p.145-157.

GLYNOS, J. \& STAVRAKAKIS, Y. (2001). Posturas e imposturas: o estilo de Lacan e sua utilização da matemática. Ágora, July/Dec. 2001, 4 (2), p.111-130.

HEIDEGGER, M. (2001) Seminários de Zollikon. Ed. Medard Boss. São Paulo/ Petrópolis (RJ): Educ/Vozes.

KANT, I. (1983/1787). Crítica da razão pura. São Paulo: Abril Cultural.

KAUFMANN, P. (1996). Dicionário enciclopédico de psicanálise. Rio de Janeiro: Jorge Zahar.

LACAN, J. (1966) Écrits. Paris: Seuil.

$(1953 / 1966)$. "Fonction et champ de la parole et du langage en psychanalyse”, p.237-322.

(1998) Escritos. Rio de Janeiro: Jorge Zahar.

(1956/1998). "Função e campo da fala e da linguagem em psicanálise”, p.238-324.

(1966/1998). “O Seminário sobre a 'A carta roubada”, p.13-66.

(1961-1962/1996) L’Identification, Séminaire 1961-1962. Publication hors commerce. Document interne à L’Association Freudienne Internationale.

(1961-1962/2003). O Seminário, livro 9, A identificação (1961-1962).

CEF-Recife: Publicação não comercial.

(1968-1969/2008). O Seminário: livro 16: de um Outro ao outro (1968-

1969). Rio de Janeiro: Jorge Zahar.

MATHERAT, P. (2007) Des doubles parenthèses de Jacques Lacan et des triples d'Alain Didier-Weill. Retrieved in Apr, 30, 2008, from http:// perso.enst.fr/ matherat/.

PEIRCE, C. S. (1977). Semiótica. São Paulo: Perspectiva. 
POE, E. A. (1978). "A carta roubada”, in Histórias extraordinárias (p.209-232). São Paulo: Abril Cultural.

SAUSSURE, F. de. (1995/1916). Curso de Linguística geral. São Paulo: Cultrix. VAPPEREAU, J. M. (1997). Estofa: las superfícies topológicas intrínsecas. Buenos Aires: Kliné.

ZIZEK, S. (1997) The plague of fantasies. Londres: Verso.

\author{
Marta Regina de Leão D’Agord \\ marta.dagord@ufrgs.br
}


